\title{
Functionalization and characterization of cotton with phase change materials and thyme oil encapsulated in beta-cyclodextrins
}

Fabio Alexandre Pereira Scacchetti ${ }^{1,2}$; Eugénia Pinto ${ }^{3,4}$, Graça Maria Barbosa Soares ${ }^{2}$

${ }^{1}$ Department of Textile Engineering, Federal University of Technology-Paraná, Apucarana, Brazil

${ }^{2}$ Center for Textile Science and Technology, Department of Textile Engineering, University of Minho, Guimarães, Portugal

${ }^{3}$ Interdisciplinary Centre of Marine and Environmental Research (CIIMAR/CIMAR), University of Porto, Porto, Portugal

${ }^{4}$ Laboratory of Microbiology, Biological Sciences Department, Faculty of Pharmacy, University of Porto, Porto, Portugal

\begin{abstract}
The aim of this work was to study the production of comfortable cotton plain-weave fabrics with antibacterial and antifungal characteristics through a simple finishing process, which consists in applying microcapsules of phase change materials (mPCM), monochlorotriazinyl- $\beta$-cyclodextrin $(\mathrm{MCT}-\beta-\mathrm{CD})$ and thyme oil. The fabrics were characterized by Infrared Spectroscopy (FTIR), Differential Scanning Calorimetry (DSC), Contact Angle and Infrared Thermography. The thyme oil release was also analyzed, as well as the antibacterial and antifungal activity. The materials treated with $20 \mu \mathrm{L} / \mathrm{mL}$ of thyme oil have shown anomalous oil release mechanisms, according to the Korsmeyer-Peppas model, and activity against Staphylococcus aureus, Escherichia coli, Trichophyton rubrum, Pseudomonas aeruginosa and Candida albicans.
\end{abstract}

Therefore, it was reached the conclusion that $\mathrm{MPCM}$, conjugated with thyme oil encapsulated in MCT- $\beta-\mathrm{CD}$, proved to be an interesting option to produce materials possessing thermoregulation properties with putative clinical relevance for the prevention of infections, particularly dermatophytosis. 
Keywords cotton; thyme oil; monochlorotriazinyl- $\beta$-cyclodextrin; phase change materials; antifungal; antibacterial.

\section{Introduction}

There is an increase in the number of studies about textiles with properties such as the ability to repel water and dirt, thermal comfort, resistance to the fire and inhibition of microorganisms, for example, looking for high quality products resulting from the combination of new materials with technologies $[1,2]$. Functionalization in textiles is an effective way to improve or add properties to modify their behavior. Currently, there are many studies concerning functionalized textiles, taking advantage of both the large surface area of textiles and the possibility to produce biodegradable and biocompatible structures. [3-5].

The use of phase change materials (PCMs) in textiles provides a thermoregulation system, developed to regulate the variations of temperature of the human body. Hence, by ensuring to the body a comfortable temperature through the wearing of these textiles, they promote comfort to the user, especially in the unfavorable environments [6-8].

An increasingly more adopted concept for the modification of textile substrates is based on the permanent bond of compounds, such as microcapsules and cyclodextrins (CD), on the surface of the material. Among the components of the microcapsules that can be added, the highlight is for PCMs. They are characterized by having a phase change in a given temperature range, which leads to the storing or transferring of thermal energy. Due to latent heat, the microcapsules can store and release energy, which occurs without significant change in temperature allowing an insulation effect [9-11].

CD provides hosting cavities that can include a large variety of guest molecules for specific functionalities. This finishing strategy offers the textiles new properties such as antimicrobial, anti-UV, cosmetic, and others, and is particularly useful for stabilizing active agents $[12,13]$. They are cyclic sugars obtained through the enzymatic degradation of starch, being that $\alpha, \beta$ 
and $\gamma \mathrm{CD}$ with 6, 7 and 8 glucose units respectively are the most common. Nevertheless, $\beta$-CD is the widely used in textile finishing due to the more suitable cavity diameter that allows the formation of stable inclusions of complexes with a large number of compounds [14-18]. The inclusion mechanism involves the displacement of water from the hydrophobic cavity by the hydrophobic guest molecule. Host-guest complexes are energy favorable [19,20].

Among all $\beta$-CD derivations, monochlorotriazine-beta-cyclodextrin (MCT- $\beta$-CD) is the most interesting to be utilized in cellulosic substrates due to the simple attachment process under relatively smooth conditions. Monochlorotriazinyl groups of CD react through covalent bond with nucleophilic groups, such as hydroxyl groups, of cellulose [21,22].

Superficial infections by fungi and bacteria are very common. Dermatophytic infections affect 20 to $25 \%$ of the world population and constitute a serious public health problem. These dermatophyte fungi metabolize the keratin present on human epidermis, hair and nails. Fungal nail infection, onychomycosis, accounts for $50 \%$ of all nail infections. Tinea pedis, also known as athlete's foot, is connected with highly contagious fungi. Trichophyton rubrum and Trichophyton mentagrophytes are the species more frequently involved. Yeasts, particularly Candida albicans and Candida parapsilosis, are also relevant infectious agents. Besides inflammation, the damaged tissue resulting from the infection becomes more vulnerable to bacterial infections and species such as Staphylococcus aureus and Pseudomonas aeruginosa can be involved as primary or secondary infectious agents $[23,24]$

Plant extracts, essential oils and their active compounds have been isolated, identified and characterized, considering the acknowledgement of the importance of plant-based materials as potentially non-toxic and non-allergenic antimicrobial materials. Several medicinal plants such as Mentha piperita, Thymus vulgaris, Origanum compactum, Salvia officinalis, Artemisia absinthium and Lavandula angustifolia have been studied [25-29]. Among these natural biocides, thyme oil (from Thymus vulgaris L.) has been suggested to possess high antimicrobial, phytotoxic and insecticidal properties, which can be attributed to the presence of phenolic 
compounds, especially thymol (5-methyl-2-(1-methylethyl)phenol) and carvacrol (2-methyl-5(1-methylethyl)-phenol) [30-34].

Hence, the aim of our study was to prepare and characterize cotton fabrics possessing thermal comfort together with antibacterial and antifungal properties through the combination of microcapsules of PCMs, MCT- $\beta-\mathrm{CD}$ and thyme oil in a simple application process. The interest in the design and optimization of these multifunctional materials is obvious, as far as we know even to the best of our knowledge, this combination of products has never been properly analyzed in textile finishing.

\section{Measurements and characterizations}

The samples utilized were composed of plain-weave bleached taffeta cotton fabrics, $585 \mathrm{~g} / \mathrm{m}^{2}$, supplied by Textile Belém, Brazil.

In this work, the thyme oil (composed of $44.88 \%$ thymol, $20.53 \% p$-cymene, $14.27 \% \gamma$ terpinene, $5.98 \%$ linalool, $4.6 \%$ carvacrol and $9.74 \%$ of others components) was obtained from Soria Natural S. A. (Spain) and MCT- $\beta-C D$ from Wacker \& Chemie Ltd., Spain.

The melamine-formaldehyde (MF) microcapsules of phase change materials (mPCMs) were supplied by Micrópolis Devan (Portugal). Phenolphthalein was supplied by Panreac, Montplet \& Esteban S.A., Spain.

All other reagents, such as ethanol and sodium carbonate, of analytical grade, were purchased from Sigma-Aldrich, Portugal.

\subsection{Measurements}

\subsubsection{Functionalization of cotton with MCT- $\beta-C D$ and mPCMs}

MCT- $\beta$-CD were applied by conventional pad-dry-cure method. A MCT- $\beta$-CD solution (30 $\mathrm{g} / \mathrm{L} ; \mathrm{pH} 4$ ) was applied by impregnation in a Foulard Roaches (4 bar, 6 m/min, pick-up 90\%). Samples were dried and cured in Warner Mathis AG, Stenter at $150^{\circ} \mathrm{C}$ during 5 minutes. $\mathrm{mPCM}$ 
(300 g/L) and MCT- $\beta$-CDs (30 g/L) were applied in a single bath (pH 4) by conventional paddry-cure process. The samples were impregnated with solution in Foulard Roaches (4 bar, 6 $\mathrm{m} / \mathrm{min}$, pick-up $90 \%$ ), dried and cured at $140^{\circ} \mathrm{C}$ during 2 minutes. Finally, they were rinsed thoroughly using hot tap water, followed by cold tap water for $10 \mathrm{~min}$ and dried in air conditioning.

\subsubsection{Evaluation of MCT- $\beta-C D$ fixation on cotton samples}

The MCT- $\beta-C D$ quantification on fabrics was made indirectly, through the phenolphthalein method $[18,35,36]$. Succinctly, this method is based on the decrease of the absorbance of the phenolphthalein alkaline solution due to the presence of $\mathrm{CD}$. Phenolphthalein can form 1:1 complexes with CD resulting in a change in color, measured with a UV-2101PC Shimadzu spectrophotometer (Kyoto, Japan).

The phenolphthalein solution was prepared by dissolving $0.1 \mathrm{~g}$ in ethanol $(100 \mathrm{~mL})$. The solution was stirred for 30 minutes at $30^{\circ} \mathrm{C}$. Then, a buffer solution (sodium carbonate $52.8 \mathrm{~g} / \mathrm{L}$ and sodium bicarbonate $8.4 \mathrm{~g} / \mathrm{L} ; 1000 \mathrm{~mL}$ ) was added to achieve a final concentration of $3.2 \mathrm{e}^{-5} \mathrm{M}$. The resulting work solution was stored and kept protected from light.

The alkaline solution of phenolphthalein $\left(\mathrm{pH} 10.5,30 \mathrm{~mL}\right.$ of $3.2 \mathrm{e}^{5} \mathrm{M}$ ) was added to a flask containing a sample of MCT- $\beta$-CD-cotton fabrics (1g). After mixing for 3 hours at $25^{\circ} \mathrm{C}$, the absorbance of the solution was measured at $553 \mathrm{~nm}$ and the MCT- $\beta$-CD quantification was calculated according to the curve calibration previously made. Three independent measurements were made from each concentration. 


\subsubsection{Thyme oil application}

Modified and unmodified samples with MCT- $\beta$-CD were immersed in a solution composed of ethanol/water (60:40) containing thyme oil (2\%) and put under spinning during 20 minutes. Afterward, they were squeezed on Foulard (pick-up 90\%).

The reference samples were treated with ethanol/water (60:40) solution only. After padding, the samples of fabrics were washed in tap water and dried at room temperature.

\subsection{Samples characterization}

\subsubsection{FTIR Spectroscopy}

Attenuated total reflection Fourier Transform Infrared spectra (ATR-FTIR) of untreated cotton, cotton treated with MCT- $\beta$-CD loaded with thyme oil, and cotton treated with MCT- $\beta$-CD with mPCM were recorded on ATR-FTIR Avatar 360 spectrophotometer (Madison, USA). KBr windows of MCT- $\beta-\mathrm{CD}$ were made. MPCM and Thymus vulgaris oil were dried and analyzed using $\mathrm{NaCl}$ windows in the same equipment. Each spectrum was scanned 60 times with a resolution of $16 \mathrm{~cm}^{-1}$.

\subsubsection{DSC analysis}

DSC analyses were performed with a differential scanning calorimeter Mettler Toledo DSC$822^{\mathrm{e}}$ instrument (Giessen, Germany). Melting point and heat of fusion calibration were carried out with indium under nitrogen atmosphere $(80 \mathrm{~mL} / \mathrm{min})$. A heating rate of $10^{\circ} \mathrm{C} / \mathrm{min}$ going from $25^{\circ} \mathrm{C}$ to $400^{\circ} \mathrm{C}$ was used to investigate the inclusion complex with MCT- $\beta$-CD.

A heating rate of $10^{\circ} \mathrm{C} / \mathrm{min}$ going from $0^{\circ} \mathrm{C}$ to $50^{\circ} \mathrm{C}$ was used to examine the thermoregulation effect of the fabrics containing mPCM. All the tests were performed thrice and the average values were recorded. The DSC analyses have covered random areas of each sample and an empty pan was used as the standard reference. Analyses were performed under a nitrogen purge. The weight of each sample was kept constant $(5.7 \pm 0.1 \mathrm{mg})$. 


\subsubsection{Infrared thermography}

The thermo-regulating properties of textiles were determined by using an infrared camera Testo 876 (Lenzkirch, Germany). This equipment allows to measure thermal images between $20^{\circ} \mathrm{C}$ to $250^{\circ} \mathrm{C}$, with a precision of $\pm 2^{\circ} \mathrm{C}$. The samples were carefully placed on the preheating hotplate VWR professional (Pennsylvania, USA), at $33^{\circ} \mathrm{C}$ to simulate the skin temperature [8]. The images of the samples were recorded and treated using the IRsoft software to measure the time delay to reach the same temperature.

\subsubsection{Fastness to rubbing}

The standard ISO 105-X12:2016, which describes a method for determining the resistance of the color in textiles, was adapted in order to analyze the influence of the friction in the thermoregulation of the samples treated with mPCM.

Tests were performed in triplicate with a dry rubbing cloth during 10 cycles, according to the standard. The results were analyzed by comparing DSC thermograms of samples before and after the rubbing test.

\subsubsection{Static and dynamic contact angles}

The contact angle measurement was analyzed in a Dataphysics instrument (Filderstadt, Germany) with the OCA20 software. The samples were measured ten times each. The method consists basically in forming a water drop, with a specific quantity, and measure the contact angle between the drop and the material surface after a certain time [37,38].

\subsubsection{Testing of antimicrobial efficiency}

The bacteria used were Escherichia coli ATCC $^{\circledR} 25922^{\mathrm{TM}}$, Staphylococcus aureus AATCC ${ }^{\circledR}$ $6538^{\mathrm{TM}}$, and Pseudomonas aeruginosa $\mathrm{ATCC}^{\circledR} 27853^{\mathrm{TM}}$. The fungi strains tested were Candida 
albicans ATCC $^{\circledR} 10231^{\mathrm{TM}}$ and Trichophyton rubrum (a clinical isolate from skin dermatophytosis-FF9).

The antimicrobial activity of the samples was tested against bacteria and fungi strains using selective/differential media by agar diffusion methods. Bacteria were cultivated in Mac Conkey Agar (MAC-Liofilchem Diagnostic) for E. coli and P. aeruginosa and Manitol Salt Agar (MSA-Liofilchem Diagnostic) for S. aureus. Sabouraud Dextrose Agar (SDA-Biomérieux) was used for C. albicans and Mycosel Agar (MYC-Becton Dickinson) for T. rubrum. Overnight cultures of bacteria and 24 hour cultures of yeasts on Tryptic Soy Agar (TSA-Liofilchem Diagnostic), or SDA, respectively, were used to prepare a cell suspension in a sterile $0.85 \%$ saline solution at the standard density of $0.5 \mathrm{Mc}$ Farland. The inoculum contained microorganisms in the range of $1-1.5 \times 10^{8}$ colony forming units (CFU)/mL. For dermatophytes, a spore suspension was prepared in a $0.85 \%$ sterile saline solution with tween 80 , counted in a Neubauer chamber, to about $2.5-6 \times 10^{5} \mathrm{CFU} / \mathrm{mL}$.

Briefly, the plates containing adequate culture agar medium were inoculated by spreading on the surface with each of the inoculum microorganisms to be tested and dried for $15 \mathrm{~min}$. Fabrics $(15 \mathrm{~mm})$ sterilized by ultra-violet (UV) radiation were placed over the center of the plates.

Plates of bacteria were incubated during 24 hours at $37^{\circ} \mathrm{C}$, yeasts during 48 hours at $37^{\circ} \mathrm{C}$, and dermatophytes during 5-7 days at $28^{\circ} \mathrm{C}$.

Zones of inhibition or absence of growth reveal the antimicrobial activity. The inhibition was assessed from the zone formed in and around the fabric.

Sterilized swatches, treated or not with etanol:water (60:40) solutions, were used as negative controls in each experiment. A positive control, through the immersion of the untreated samples in a commercial thyme oil and dried at $37^{\circ} \mathrm{C}$ for 24 hours was also performed. 
2.2.7. Determination of minimal inhibitory concentration (MIC) for T. vulgaris essential oil The minimal inhibitory concentration for T. vulgaris was evaluated according to CLSI standard tests for bacteria, yeasts and fungi, M07-A9, M27-A2 and M38-A2, respectively.

\subsubsection{Controlled release of thyme oil}

The in vitro evaluation of the thyme oil release profile on textile substrates was determined. After functionalization, the cotton fabrics were placed in an alkaline solution that mimics human perspiration according to the ISO $105 \mathrm{E} 04$, thermostated at $37^{\circ} \mathrm{C} \pm 5^{\circ} \mathrm{C}$ under constant stirring on Agimatic Selecta (Spain). This alkaline solution is composed of $0.5 \mathrm{~g} / \mathrm{L}$ of Lhistidine monohydrochloride monohydrate $\left(\mathrm{C}_{6} \mathrm{H}_{9} \mathrm{O}_{2} \mathrm{~N}_{3} \cdot \mathrm{HCl} \cdot \mathrm{H}_{2} \mathrm{O}\right) ; 5 \mathrm{~g}$ of sodium chloride $(\mathrm{NaCl})$; and also $5 \mathrm{~g} / \mathrm{L}$ of disodium hydrogen orthophosphate dodecahydrate $\left(\mathrm{Na}_{2} \mathrm{HPO}_{4} \cdot 12 \mathrm{H}_{2} \mathrm{O}\right)$. The solution is brought to $\mathrm{pH} 8( \pm 0.2)$ with $0.1 \mathrm{~mol} / \mathrm{L}$ sodium hydroxide solution.

Aliquots of $2 \mathrm{~mL}$ were taken at predetermined times in order to read the absorbance spectroscopy in the ultraviolet range, $275 \mathrm{~nm}$, using a UV-VIS spectrophotometer Shimadzu UV-2101PC (Japan). All tests were performed thrice and the average values were calculated.

The mathematical setting used for the evaluation of drug release was from the model of Korsmeyer et al. [39]. The statistical analysis was obtained through the graphical simulation in OriginPro 8.5.1.

\section{Results and discussion}

3.1. Functionalization of cotton with mPCM, MCT- $\beta-C D$ and thyme oil MCT- $\beta$-CD and $\mathrm{mPCM}$ were applied to cotton through a padding process in a single step. The monochlorotriazinyl group of CD reacts with the hydroxyl groups of cellulose through a substitution nucleophilic mechanism. Briefly, the O- groups of cellulose attack the heterocyclic carbon of the reactive group, the nucleophilic group is replaced by the halogen of triazine and 
a covalent bond is created [18]. Through a simple acidic or alkaline impregnation, followed by the curing or exhaustion processes, it is possible to achieve suitable fixation yield of MCT- $\beta$ $\mathrm{CD}$ on cellulose despite the secondary reaction of hydrolysis. Therefore, this chemical strategy is common to functionalize cotton [40]. However, by our knowledge, no data was available about the application of MCT- $\beta-\mathrm{CD}$ and $\mathrm{mPCM}$ together.

The MCT- $\beta-C D$ attached on cotton with encapsulation capacity was quantified by the phenolphthalein test as described on materials and methods. It were compared the results when the $\mathrm{CD}$ was applied alone or combined with the $\mathrm{mPCM}$ in the same bath and under similar process conditions. The results obtained from the CD applied in cotton $(30 \mathrm{~g} / \mathrm{L})$ were $6.81 \mathrm{e}^{-7} \pm$ $0.04 \mathrm{e}-8 \mathrm{~mol} \mathrm{CD} / \mathrm{g}$ of fabric $(0.77 \pm 0.03 \mathrm{mg} \mathrm{CD} / \mathrm{g}$ of fabric $)$, and from the $\mathrm{CD}$ applied conjugated with $\mathrm{mPCM}$ were $5.78 \mathrm{e}^{-7} \pm 0.06 \mathrm{e}-8 \mathrm{~mol} \mathrm{CD} / \mathrm{g}$ of fabric $(0.66 \pm 0.02 \mathrm{mg} \mathrm{CD} / \mathrm{g}$ of fabric). A slight decrease of fixation of $\mathrm{CD}$ was observed when together with the mPCM presence, which is justified by some interference on the accessibility to the bond sites on the surface of cellulose. However, the fixation obtained for CD is in accordance with the results reported by Bhaskara et al. [20], who achieved $1.47 \mathrm{e}^{-6}$ moles/g of cotton but using $40 \mathrm{~g} / \mathrm{L}$ of CD solution. From a gravimetric analysis, the amount of mPCMs on fabric was $\underline{\mathrm{s}} 8.7 \pm 2.4 \%$ (w/w) when applied alone and $8.38 \pm 2.0 \%(\mathrm{w} / \mathrm{w})$ when applied with CDs, according to the gravimetric tests (results not shown). The slight difference noted can be explained by the competition of both compounds for the link sites on fiber.

CDs are able to form inclusion complexes with oil molecules [15]. Moreover, $\beta$-CD cavity size is suitable for complex drugs with molecular weights between 200 and $800 \mathrm{~g} / \mathrm{mol}$ by noncovalent interactions like hydrophobic interactions, van der Waals-London dispersion forces, and hydrogen bonds $[41,42]$.

Thyme oil has proven to possess benefits in medical, cosmetic, veterinarian, agricultural and food related applications [43-45]. Despite thymol and carvacrol, alone or combined, be effective against bacteria and fungi, their antimicrobial applications still face chemical 
reactivity problems, limited water solubility and also short-term availability, due to their volatile properties. Inclusion in CDs exerts a profound effect on the physicochemical properties of guests, namely solubility enhancement and stability effects. Besides, several recent studies have demonstrated the complexation of carvacrol and thymol in $\beta$-CD derivatives [17,46-49]. Based on the previously mentioned, it is expected that the carvacrol and thymol can be encapsulated in MCT- $\beta-\mathrm{CD}$ on the surface of cotton.

Thyme oil, composed of thymol (44.88\%) and carvacrol (4.6\%), was applied to MCT-CDfabrics in defined conditions to prevent evaporation of the label components. The oil application was made with the assumption that $\beta-C D$ can encapsulate carvacrol and thymol [34,50-52]. In fact, the interaction of $\beta-\mathrm{CD}$ and carvacrol in aqueous solution, results in a 1:1 complex, in which the isopropyl group of the molecule is located closer to the larger side of the hydrophobic cavity of $\beta$-CD. Thymol can also be encapsulated in $\beta$-CD very efficiently and with a constant stability of $618 \mathrm{M}^{-1}[53]$.

The complex formation for the active compounds in the extracts is significantly lower when comparing with pure molecules of carvacrol and thymol, in view of the fact that the presence of other compounds in the extract could compete for inclusion reactions with the $\beta-C D$. Although the sample molecules have different equilibria in the solution, to force them to form complexes, thymol and carvacrol, present in thyme essential oil, encapsulate as previously reported by Tao et al. [54]. Moreover, it should be noted that these compounds together make up $49.5 \%$ of its composition.

\subsection{FTIR spectral analysis}

The finished materials were characterized by ATR-FTIR. Figure 1a, b and c present the FTIR spectra of the thyme oil, MCT- $\beta-C D$ and $\mathrm{MPCM}$, the key components used in the functionalization of cotton fabrics. As oil is majority composed of thymol and carvacrol, the presence of phenolic $\mathrm{OH}$ group is observed with a band that corresponds to $3400 \mathrm{~cm}^{-1}$ due to - 
$\mathrm{OH}$ stretching vibration involving hydrogen bonding. Aromatic character of terpenes was exhibited by $-\mathrm{C}=\mathrm{C}$ stretching of benzene ring at $1619 \mathrm{~cm}^{-1}$ (Fig. 1a). The bending vibration of $-\mathrm{OH}$ and $-\mathrm{C}-\mathrm{O}$ stretching of phenolic group occurred as peaks at $1419 \mathrm{~cm}^{-1}$ and $1234 \mathrm{~cm}^{-1}$. Rukmani and Sundrarajan [47] obtained similar results, except a small band deviation (3392 $\mathrm{cm}^{-1}, 1625 \mathrm{~cm}^{-1}, 1360 \mathrm{~cm}^{-1}$ and $1222 \mathrm{~cm}^{-1}$ respectively).
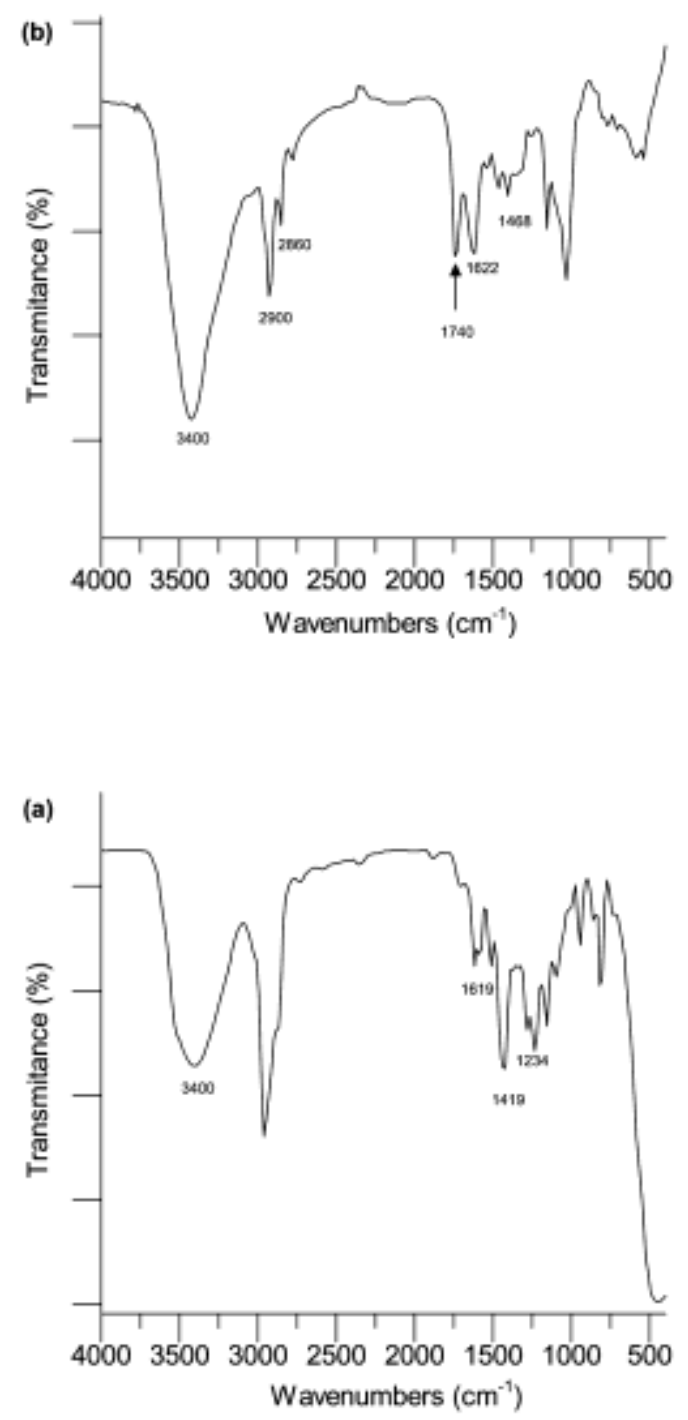


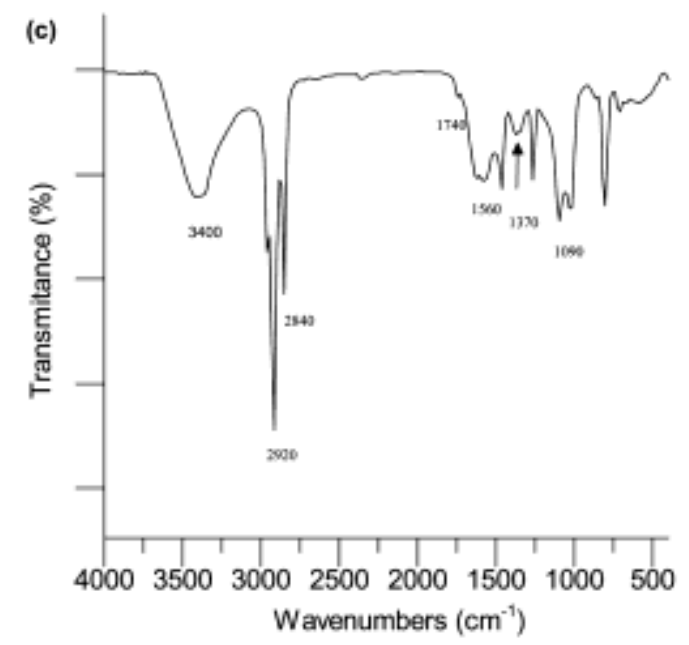

Fig. 1. FTIR spectra of: (a) thyme oil, (b) MCT- $\beta$-cyclodextrin and (c) mPCMs

The spectrum of MCT- $\beta$-CD (Fig.1b) shows $-\mathrm{OH}$ stretching of cyclodextrin moiety at 3400 $\mathrm{cm}^{-1}$ and $\mathrm{C}-\mathrm{H}$ stretching at 2940 and $2860 \mathrm{~cm}^{-1}$. The absorption band at $1740 \mathrm{~cm}^{-1}$ can be assigned to the $-\mathrm{C}=\mathrm{N}$ stretching vibration triazinyl group of MCT- $\beta-\mathrm{CD}$ [55]. The band related to the triazinyl ring without any substitution is at $1350-1587 \mathrm{~cm}^{-1}$. However, with $\mathrm{Cl}$ or $\mathrm{CD}$ as side chains, the bands shift to $1400-1650 \mathrm{~cm}^{-1}$. Consequently, the peak observed at around 1468 and $1622 \mathrm{~cm}^{-1}$ is assigned to the stretching vibration of $\mathrm{C}=\mathrm{N}$ [56].

The spectrum of mPCMs (Fig. 1c) shows an expanded absorption band at $3400 \mathrm{~cm}^{-1}$ that corresponds to elongation vibrations of the $\mathrm{OH}$ groups. The absorption peaks at $2920 \mathrm{~cm}^{-1}$ and $2840 \mathrm{~cm}^{-1}$ can be assigned to vibration of C-H elongation. The absorption peak at $1740 \mathrm{~cm}^{-1}$ can be assigned to the carbonyl group, N-H bending vibration at $1560 \mathrm{~cm}^{-1}$. The absorption band at $1370 \mathrm{~cm}^{-1}$ may correspond to the vibration of $\mathrm{C}-\mathrm{N}$ [57].

The FTIR spectra of untreated cotton and cotton functionalized with MCT- $\beta$-CD loaded with thyme oil shown in Figure 2 have similar profile (Fig. 2a). Cotton spectrum shows a broad peak at $3280 \mathrm{~cm}^{-1}$ corresponding to $-\mathrm{OH}$ stretching vibration of cellulose and an asymmetric stretching of $\mathrm{C}-\mathrm{H}$ is observed at $2900 \mathrm{~cm}^{-1}$. However, when analyzing the 1800 to $600 \mathrm{~cm}^{-1}$ spectral region (Fig. 2b), the presence of MCT-CD bonded to cotton is confirmed by the 
appearance of a small peak detected at $1715 \mathrm{~cm}^{-1}$, conjugated cyclic $>\mathrm{C}=\mathrm{N}$-systems show an absorption at waves between 1630 and $1430 \mathrm{~cm}^{-1}[18,55,58]$.
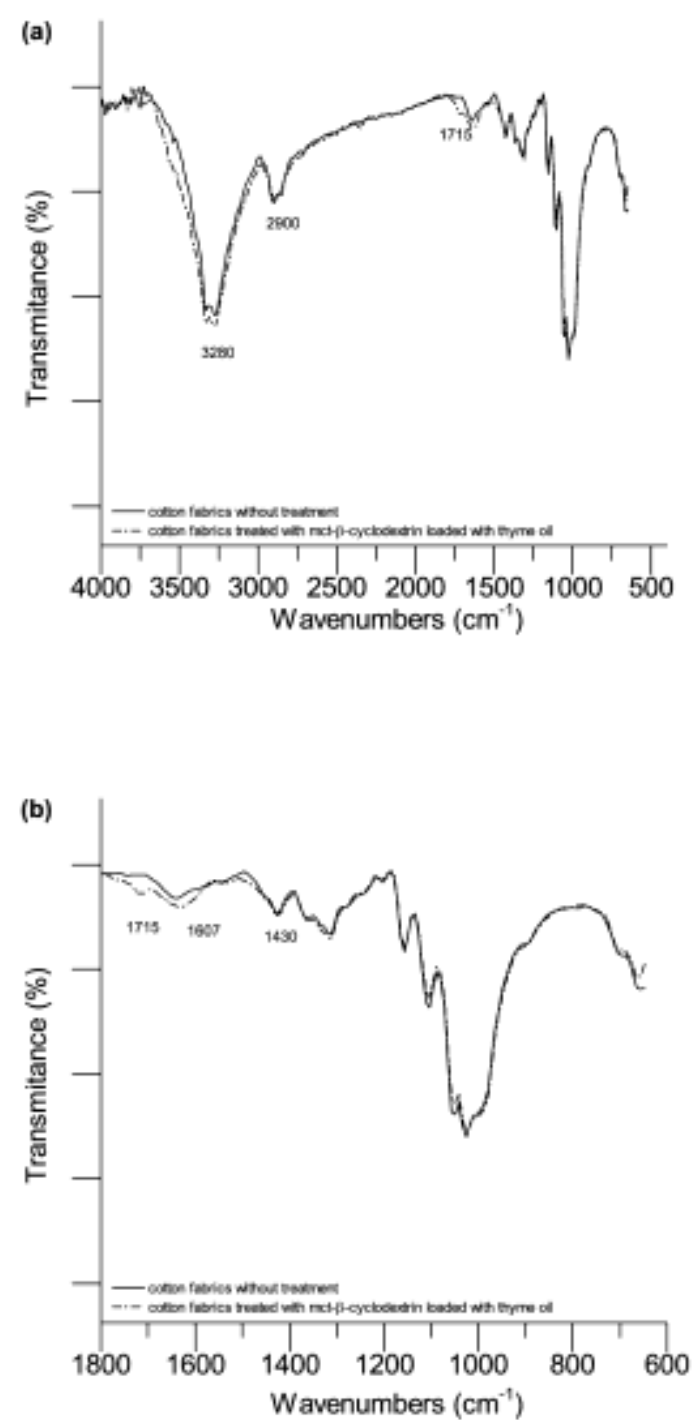

Fig. 2. FTIR spectra of cotton fabrics untreated and functionalized with MCT- $\beta-C D$ and thyme oil

The untreated cotton and the cotton treated with MPCM (Fig. 3a) and mPCMs conjugated with MCT- $\beta$-CD with thyme oil (Fig. 3b) were analyzed. It can be observed evidences of adhesion of mPCM (melanine-formaldehyde microcapsules) with reactive groups that can bind to cotton samples, mainly by increasing the intensity of the corresponding absorption band at elongation vibrations of the $\mathrm{OH}$ groups at $3280 \mathrm{~cm}^{-1}$ and $\mathrm{CH}$ at $2915 \mathrm{~cm}^{-1}$ and $2850 \mathrm{~cm}^{-1}$. 
The increased intensity of peaks is caused by the reaction originated by the addition of the radical $-\mathrm{CO}-\mathrm{CH}=\mathrm{CHR}$ present in the melamine-formaldehyde microcapsules with the $\mathrm{O}-\mathrm{H}$ groups in cellulose [59]. The $\mathrm{CH}_{3}$ deformation mode at $1262 \mathrm{~cm}^{-1}$ is considered to be the most characteristic band in the organosilicon infrared spectrum. There is a small absorption at 1262 $\mathrm{cm}^{-1}$. Also, a small peak at $810 \mathrm{~cm}^{-1}$ is related to the breakdown of Si-O-Si groups and the formation of Si-O-cellulose binding [60].
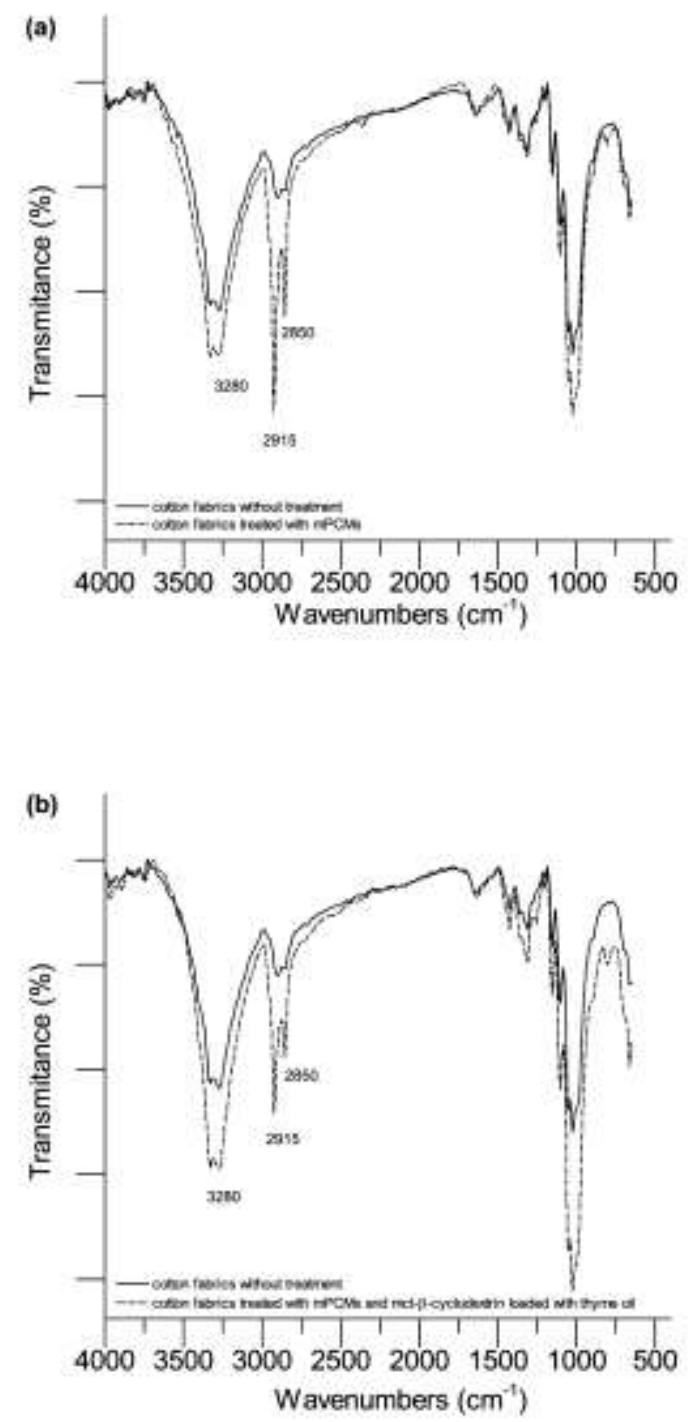

Fig. 3. FTIR spectra of (a) cotton fabrics functionalized with $\mathrm{mPCM}$ and (b) cotton fabrics functionalized with mPCM conjugated with MCT- $\beta-C D$ loaded with thyme oil 


\subsection{DSC analysis}

The thermograms of untreated cotton and cotton with MCT- $\beta-C D$ are shown in Figure 4.

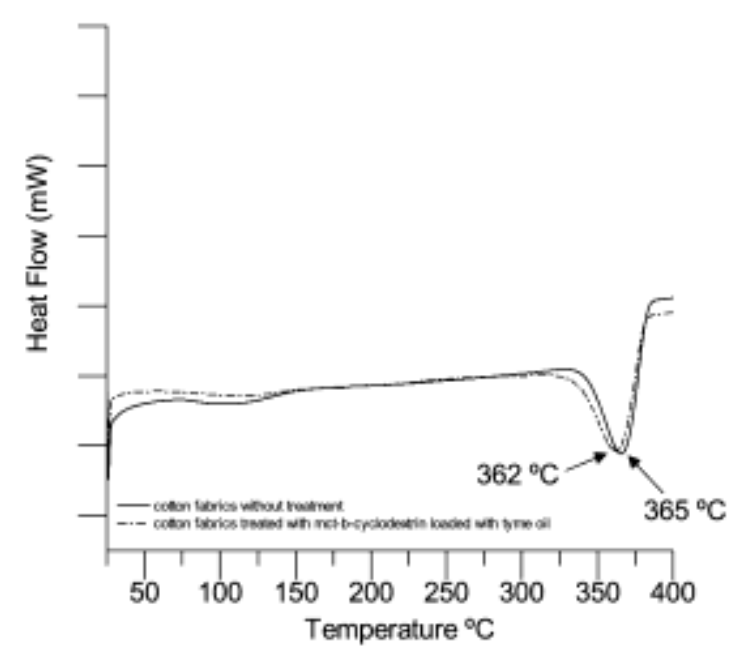

Fig. 4. DSC thermograms of untreated cotton and cotton functionalized with MCT- $\beta-C D$

Untreated cotton fabric had a strong endothermic peak at $365^{\circ} \mathrm{C}$ associated to the thermal decomposition process of cellulose. The formation of the peak starts around $333^{\circ} \mathrm{C}$ until $387^{\circ} \mathrm{C}$ approximately. For the cotton fabrics treated with MCT- $\beta-C D$ with thyme oil there was a strong peak at $362^{\circ} \mathrm{C}$, although the formation of the peak started over $320^{\circ} \mathrm{C}$ and finished at $385^{\circ} \mathrm{C}$. The advantage of a characterization using a DSC technique is the possibility to measure the thermal capacity and heat fusion of the compounds, given that the area of the thermogram peaks is directly proportional to enthalpy. The thermograph test was performed thrice and the average values of the enthalpy were calculated, showing that the enthalpy value of cotton sample was $115.75 \mathrm{~J} / \mathrm{g}$ and the enthalpy value of treated cotton was $119.87 \mathrm{~J} / \mathrm{g}$. According to Grigoriu et al. [61], this slight increase in the values of enthalpy is related to the splitting of the hydrogen bonds in the cotton fiber and also MCT- $\beta$-CD grafted to the cotton fiber of the hydroxyl groups, evidenced in this experiment.

The friction fastness (namely related to $\mathrm{mPCM}$ fastness) of functionalized fabrics was investigated. Thermograms were recorded before and after rubbing under controlled pressure 
for a specific number of times as described on standard test expressed above (Fig 5). No significant differences were observed on thermograms due to the friction.

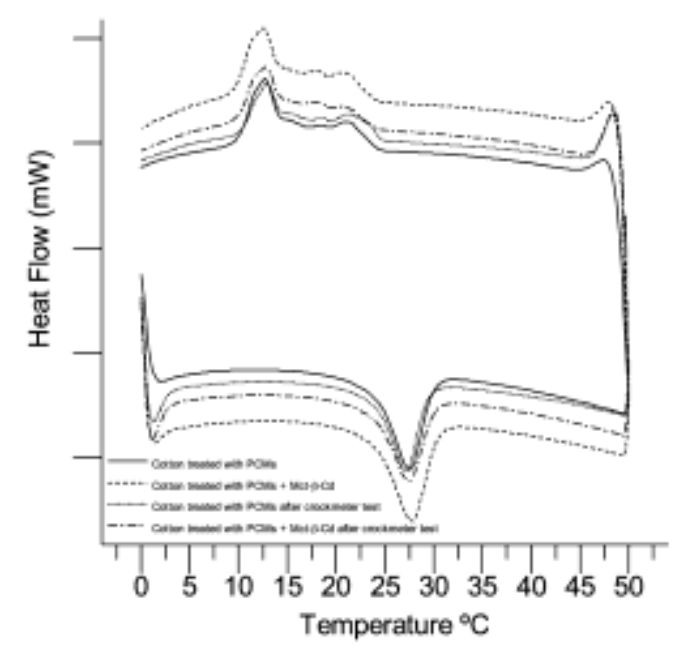

Fig. 5. DSC thermograms of cotton fabrics functionalized with $\mathrm{MPCM}$ and conjugated with mPCM and MCT- $\beta$ CD before and after rubbing test

\subsection{Thermoregulation properties of functionalized fabrics}

The thermoregulation effects shown by the performed finishing on fabrics were analyzed based on DSC analyses and tests through Infrared Thermal Camera. Analyzing the DSC thermograms of Figure 5 and Table 1, which show the average values of the thermal storage energy (latent heats), as well as the melting and crystallization transition point to the samples treated with phase change materials and associated with MCT- $\beta$-CD before and after rubbing tests, it is possible to note that all the substrates treated allow the improvement of thermo-regulating properties and latent heat storage capacities. In fact, the possibility to obtain cotton with thermoregulation properties by coating the material with $\mathrm{mPCM}$ was well described by other researchers $[2,62-64]$.

There are slight differences concerning to latent heat storage among the samples. Tests have shown that the simultaneous application of mPCM with CD did not have influence in the thermal-regulation of the fabrics; even after the friction tests, the samples continued showing a small difference, confirming the integrity of microcapsules into the textile. According to 
published studies, the thermal load and comfort in a microclimate is not influenced only by latent heat. The heat transfer through fabrics is directly related with the amount of microcapsules added in the surface, but is also related with other factors like the application method and the textile structure $[2,65]$.

Table 1 Thermal properties of cotton fabrics with MPCM and cotton fabrics with mPCM and MCT- $\beta-C D$, before and after rubbing tests

\begin{tabular}{lcccc}
\hline & $\begin{array}{c}\text { Melting } \\
\text { latent heats } \\
(\mathrm{J} / \mathrm{g})\end{array}$ & $\begin{array}{c}\text { Melting temp. } \\
\left(\text { range }{ }^{\circ} \mathrm{C}\right.\end{array}$ & $\begin{array}{c}\text { Crystallization } \\
\text { latent heats } \\
(\mathrm{J} / \mathrm{g})\end{array}$ & $\begin{array}{c}\text { Crystallization } \\
\text { temp. }(\text { range }){ }^{\circ} \mathrm{C}\end{array}$ \\
\hline Cotton with mPCM & 6.40 & $27.4(23.2-30.1)$ & 7.30 & $12.7(15.5-9.6)$ \\
$\begin{array}{l}\text { Cotton with mPCM after } \\
\text { rubbing test }\end{array}$ & 6.10 & $26.8(22.9-29.5)$ & 7.19 & $13.0(16.4-9.8)$ \\
$\begin{array}{l}\text { Cotton with mPCM and MCT- } \beta- \\
\text { CD }\end{array}$ & 6.70 & $27.7(23.4-30.6)$ & 8.68 & $12.6(15.6-9.2)$ \\
$\begin{array}{l}\text { Cotton with PCM + MCT- } \beta-C D \\
\text { after rubbing test }\end{array}$ & 6.47 & $27.7(23.2-30.4)$ & 7.93 & $12.6(15.8-9.3)$ \\
\hline
\end{tabular}

Untreated cotton and cotton treated with mPCMs and MCT- $\beta-C D$ were also analyzed with an Infrared Thermal Camera. The fabrics previously conditioned at $21^{\circ} \mathrm{C}$ were heated in a hotplate until $33^{\circ} \mathrm{C}$. The cotton functionalized with $\mathrm{MPCM}$ and MCT- $\beta-\mathrm{CD}$ showed a delay to reach the same temperature when compared with untreated cotton, allowing the confirmation of the effect of mPCM already observed on DSC thermograms. The rise of temperature was measured frame by frame based on time, which is presented in Figure 6. 


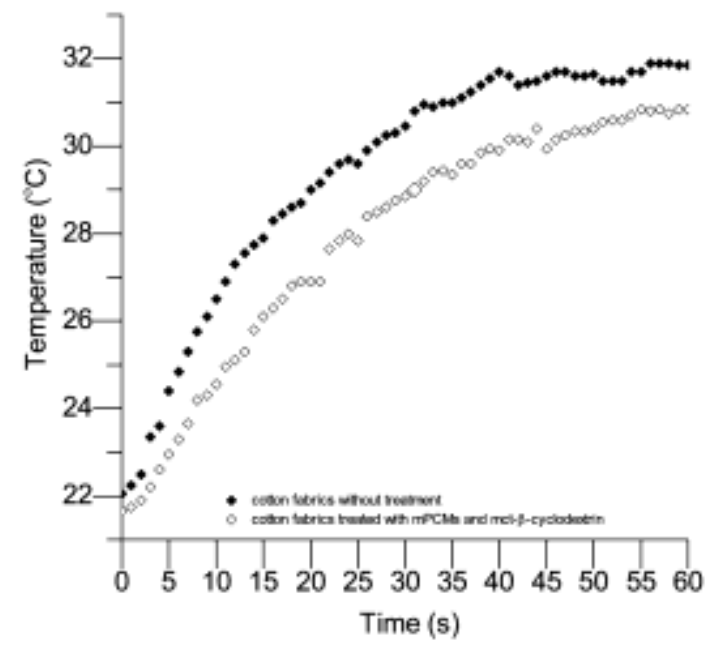

Fig. 6. Time delay to reach $33^{\circ} \mathrm{C}$ of untreated cotton and cotton functionalized with mPCM and MCT- $\beta-C D$

Cotton reached $30^{\circ} \mathrm{C}$ after 26 seconds and the temperature stabilized around $32^{\circ} \mathrm{C}$ after 60 seconds in contact with hotplate. However, the functionalized cotton reached the same temperature $\left(30^{\circ} \mathrm{C}\right)$ only after 40 seconds, though it had stabilized near to $31^{\circ} \mathrm{C}$. These results evidenced that the cotton with $\mathrm{mPCM}$ and MCT- $\beta-\mathrm{CD}$ has a better thermal performance.

\subsection{Influence of functionalization on hydrophilicity of fabrics}

The study of static and dynamic contact angle was used to measure the wetting properties of the samples. Sometimes, it is difficult to evaluate the contact angle in textiles due to the surface and structure irregularities and absorbency variations presented [66].

The wetting properties are associated with the surface tension of the liquid in contact with the surface. When a surface has sufficient polar groups, the water drop is immediately absorbed; otherwise the water drop forms a contact angle with the surface. If this contact angle is smaller than $30^{\circ}$, the surface is considered hydrophilic and if a contact angle is higher than $90^{\circ}$, the surface is considered hydrophobic $[38,67]$. 


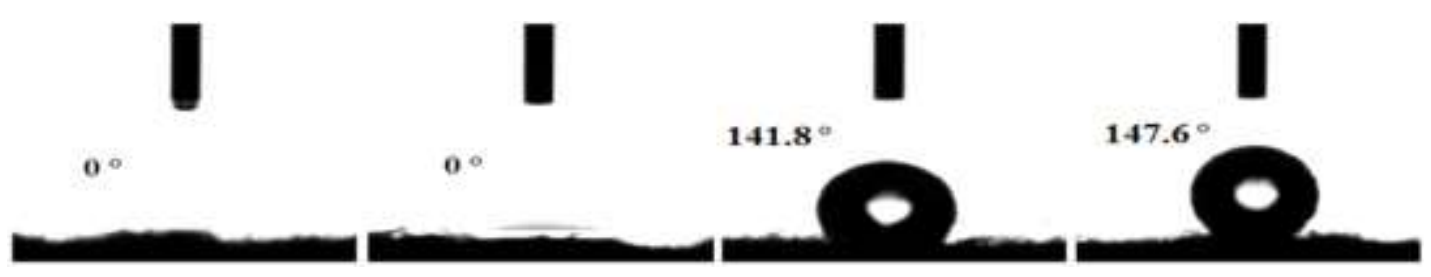

Fig. 7. Static contact angle for tested samples: (a) cotton; (b) cotton with MCT- $\beta-C D$; (c) cotton with mPCM; (d) cotton with $\mathrm{MPCM}$ and MCT- $\beta-\mathrm{CD}$

Figure 7 shows the static contact angles measured for all tested fabrics. For cotton or cotton with MCT- $\beta-C D$, the drops are immediately absorbed. Nevertheless, cotton with $\mathrm{mPCM}$ and cotton with mPCM and CD show a contact angle of $141.8^{\circ}$ and $147.6^{\circ}$ respectively. Based only in this data, these samples could be considered as having hydrophobic behavior [38]. However, considering the results of the dynamic contact angle (Fig. 8), the average time for the absorption of the water drop is of 0.8 seconds approximately. This suggests that although the hydrophilicity of the surface has decreased, the samples continued to be hydrophilic.

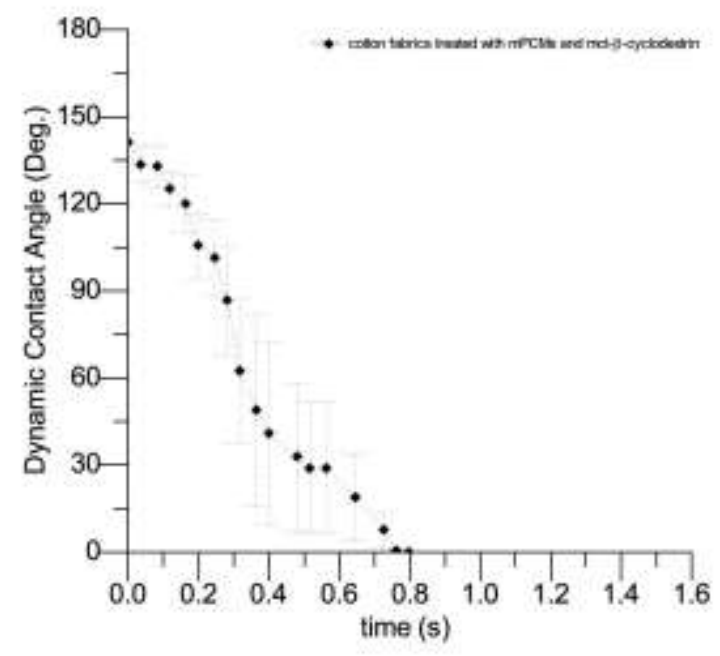

Fig. 8. Dynamic contact angles of the samples 


\subsection{Antimicrobial efficiency}

Thymus vulgaris essential oil was tested as an antimicrobial additive model due to the natural and biocompatible behavior and antimicrobial properties.

The antimicrobial activity of cotton with MCT- $\beta-\mathrm{CD}$ as well as cotton with MCT- $\beta-\mathrm{CD}$ and mPCM was evaluated as negative control and no antimicrobial activity was detected, considering all the tested microorganisms (Table 2 and Fig. 9a).

Comparing the MIC determined for the different microorganisms to T. vulgaris, according to CLSI methods, the most resistant was $P$. aeruginosa (MIC $2.5-5 \mu \mathrm{L} / \mathrm{mL}$ ) and the most susceptible was T. rubrum (MIC $0.04 \mu \mathrm{L} / \mathrm{mL}$ ). Moreover, S. aureus and E. coli showed a MIC of $0.16 \mu \mathrm{L} / \mathrm{mL}$ whereas the MIC for $C$. albicans was $0.32 \mu \mathrm{L} / \mathrm{mL}$.

As positive control, samples of cotton with MCT- $\beta$-CD and cotton with MCT- $\beta-C D$ and $\mathrm{mPCM}$ impregnated with $20 \mu \mathrm{L}$ of thyme oil were tested. All these samples exhibited strong antimicrobial activity against all the tested microorganisms (Fig. 9b).

Cotton with MCT- $\beta-\mathrm{CD}$ and cotton with MCT- $\beta-\mathrm{CD}$ and mPCM functionalized with $20 \mu \mathrm{L} /$ mL of thyme oil (samples A and B, respectively), were assessed and the results shown in Table 2 and Figure 10 are about the examples of S. aureus (similar results for E. coli), T. rubrum (similar results for P. aeruginosa) and C. albicans.

Table 2 Results of antimicrobial activity for textiles functionalized with thyme oil, using diffusion methods

\begin{tabular}{cccccc}
\hline & & \multicolumn{4}{c}{ Microorganisms } \\
& S. aureus & E. coli & P. aeruginosa & C. albicans & T. rubrum \\
\hline A & ++++ & +++ & ++ & ++ & ++ \\
B & ++++ & ++++ & + & + & +++ \\
& - & - & - & - & -
\end{tabular}

Control: samples without essential oil, treated or not with the solvent. Samples functionalized with $20 \mu \mathrm{L} / \mathrm{mL}$ of thyme oil: A- cotton with MCT- $\beta-\mathrm{CD}$; B- cotton with MCT- $\beta$-CD and mPCM. $(+/++/+++/++++)$ : Level of microorganism's growth inhibition; (-): microorganism's growth. 
The presence of MCT- $\beta$-CD did not demonstrate inhibition of all the microorganisms tested as well as the solvent (ethanol/water 60:40) used for the preparation of impregnated or functionalized samples with oil. Thus, the antimicrobial effect observed in tested samples can be attributed to the presence of thyme oil. Accordingly, the sample of thyme oil and the concentration in which it was used was able to inhibit completely, or almost completely, all the microorganisms tested, as it was possible to observe in the positive controls of samples impregnated with the same solution of essential oil used for the sample preparation.

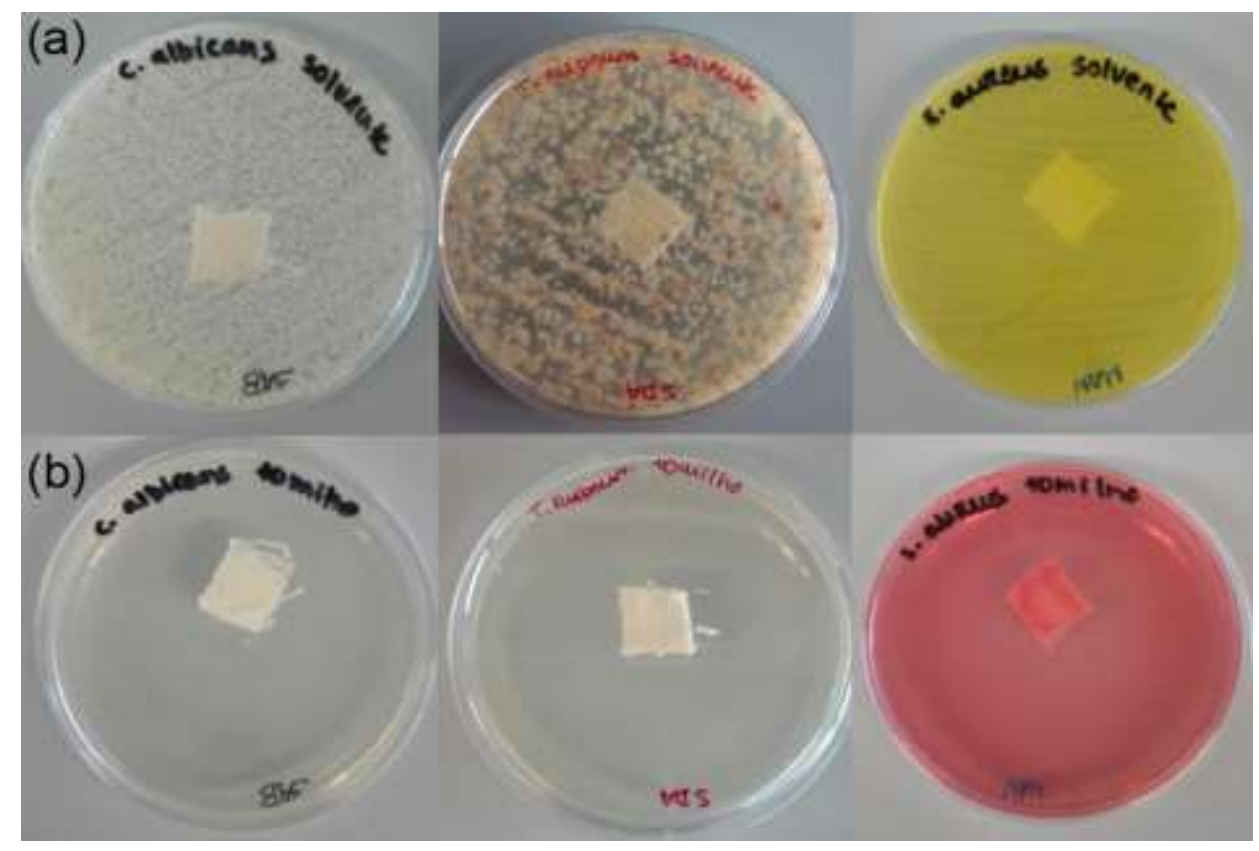

Fig. 9. Antimicrobial activity of control samples performed by diffusion methods: a-negative controls using cotton-MCT- $\beta-C D$ with solvent for $C$. albicans, T. rubrum, and $S$. aureus; b-positive controls using cottonMCT- $\beta$-CD impregnated with $20 \mu \mathrm{L}$ of thyme oil for C. albicans, T. rubrum, and S. aureus 


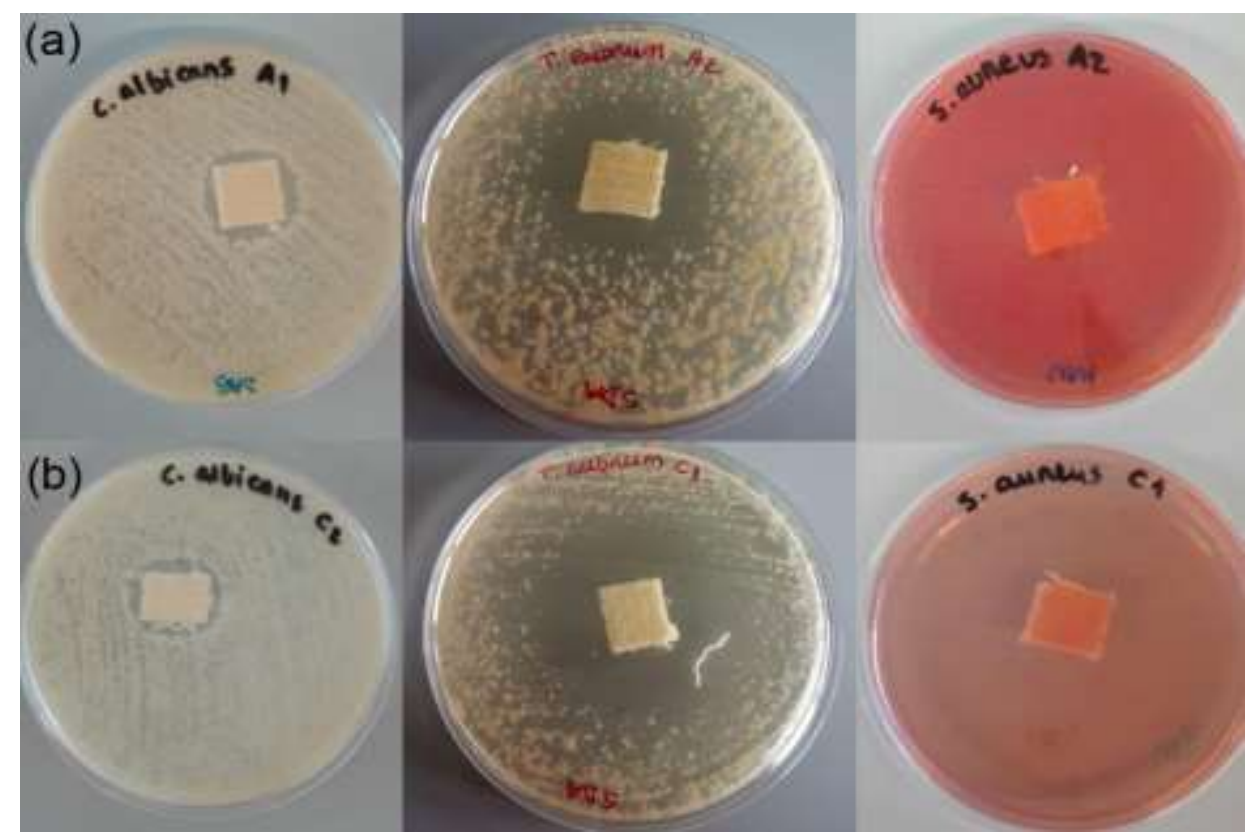

Fig. 10. Antimicrobial activity of cotton with MCT- $\beta-C D(A)$ and cotton with MCT- $\beta-C D-m P C M(B)$ functionalized with $20 \mu \mathrm{L} / \mathrm{mL}$ of thyme oil for C. albicans, T. rubrum, and S. aureus, performed by diffusion methods

Considering the obtained results, the cotton functionalized with thyme oil, inside MCT- $\beta$-CD and MCT- $\beta-C D$ with $\mathrm{mPCM}$, has shown antibacterial activity against gram-positive (S. aureus) and gram-negative (E. coli and $P$. aeruginosa) bacteria. However, $P$. aeruginosa was slightly less susceptible, which is in accordance with their higher MIC for the essential oil.

Shahidi et al. [68] evaluated the effectiveness of antimicrobials with thymol and showed $100 \%$ of effectiveness in $S$. aureus inhibition. The interaction of this agent with bacteria and yeasts seems to disrupt the cell wall or lead to the destruction of the cellular membrane with a cytoplasm leakage, eventually causing cell death $[31,69]$. Some studies have shown a higher inhibitory activity of thymol, a major component of thyme oil, against E. coli than S. aureus. The selectivity of action could be justified by the different composition and structure of the cell wall of gram-positive and gram-negative bacteria. In addition, thymol displays best antimicrobial effect while conjoined with MCT- $\beta-\mathrm{CD}$ when compared to just absorbed on the fiber surface $[47,48]$. 
Cotton with MCT- $\beta-C D$ and thyme oil and cotton with MCT- $\beta-C D$ and mPCMs and oil, seemed to be less effective against fungi than bacteria. Nevertheless, the functionalized textiles demonstrated antifungal properties against T. rubrum and C. albicans (Table 2 and Figure 9), being the dermatophyte more susceptible than the yeast.

\subsection{Release kinetics of thyme oil}

The kinetics of thyme oil release from developed textiles was analyzed. Figure 11 shows the kinetics of controlled release for the cotton fabrics with thyme oil and cotton fabrics with MCT$\beta$-CD loaded with thyme oil. The equilibrium was achieved after about 10 minutes for cotton fabrics with thyme oil and after 24 hours for cotton fabrics with oil encapsulated.

Evaluating the controlled release profile, it can be observed that there is a similar profile for both samples during the first 2 minutes with a subsequent change in the slope of the release curves. This first stage of process is often called "burst effect", where the drug releases at about $60 \%$ in both cases. The early depletion of the drug is a disadvantage regarding the intended long-term release. However, values between 10-80\%, depending on the load amount, are frequently obtained for similar applications [70].

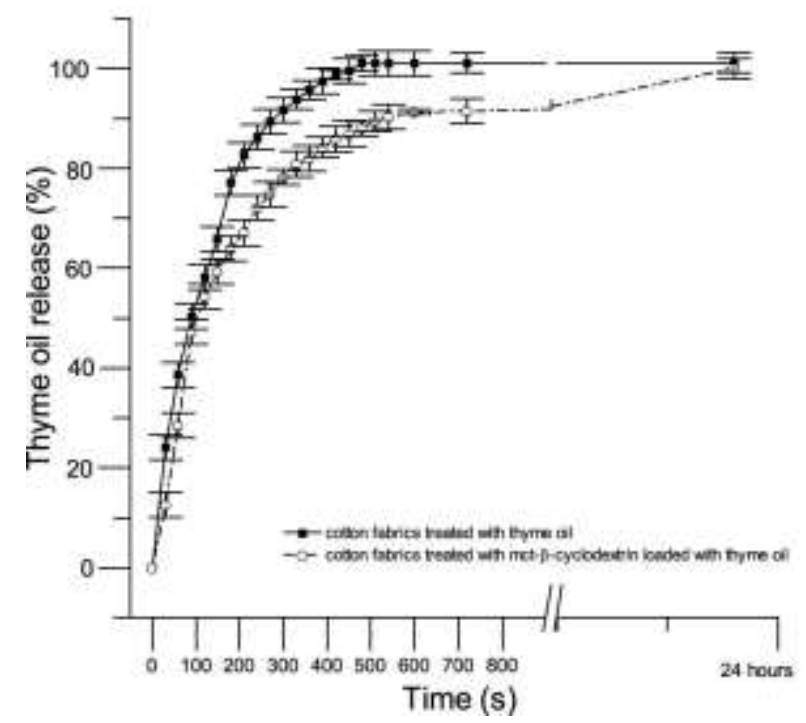

Fig. 11. In vitro controlled release profiles in alkaline solution thyme oil from cotton with thyme oil absorbed and cotton with thyme oil inside MCT- $\beta$-cyclodextrin 
The kinetic Korsmeyer-Peppas model [39] describes a rapid release rate of compounds applying the equation below and it is a very useful tool to describe release systems. In the equation (1) $n$ is a diffusion exponent indicating the type of release mechanism considering the textile structures as cylinders or materials with non-planar geometries. If $n$ is 0.45 , the release of drug occurs by a Fickian diffusion process; however, if $n$ is $0.45<n<1.0$ the diffusion process is anomalous. $n=1.0$ non-Fickian diffusion process should be considered [3,71].

$\frac{M_{t}}{M_{\infty}}=K t^{n}$

Additionally the model is highly accepted by the scientific community for its simplicity [72]. Considering a drug release of around $80 \%$ and using the Korsmeyer-Peppas equation, the main parameters $K$ and $n$ have been calculated. For cotton fabrics treated with thyme oil, the correlation coefficient was $\mathrm{R}^{2}=0.9976$, chi-square 0.0001 , and the score obtained $K=0.0293$ \pm 0.0031 and $n=0.620 \pm 0.0220$. For cotton fabrics treated with MCT- $\beta$-CD loaded with thyme oil, the correlation coefficient was $\mathrm{R}^{2}=0.9657$ and chi-square 0.0023 . According to the score $K=0.0360 \pm 0.0100, n=0.5444 \pm 0.0510$. Based on this parameters, the release of oil follows anomalous diffusion mechanisms in both situations [71]. The release mechanism is based on the morphology, concentration and distribution of the drug, and also on the hydrophobicity or hydrophilic of the matrix material [73]. The anomalous mechanism is expected to hydrophilic fibers as well as cellulosic fibers, whereas the excellent affinity with water propitiates the relaxation of chains, modifying the interactions and providing different types of release of the drug [74].

\section{Conclusions}

Cotton plain-weave fabrics that combine thermoregulation properties with antimicrobial activity against $S$. aureus, E. coli, $P$. aeruginosa, $T$. rubrum, and $C$. albicans were obtained by a simple finishing method. For that purpose, microcapsules PCM and monochlorotriazinyl- $\beta$ - 
cyclodextrin were applied in the same bath and the resulting materials were impregnated with thyme oil as a model active agent.

The oil released from functionalized fabrics was analyzed using Korsmeyer-Peppas model and it was found that the mechanism was anomalous. Additionally, it was found that modified material retains thermal properties after the rubbing action and remain hydrophilic in the end of the finishing process. Therefore, it is supposed that these comfortable cotton materials developed with modulated antimicrobial properties may eventually be used in several areas of health and biomedical applications.

\section{Acknowledgments}

The main author wishes to express thanks to the CNPq-Brazil (Conselho Nacional de Desenvolvimento Científico e Tecnológico - Brasil / National Council of Scientific and Technological Development - Brazil) for the doctoral scholarship (233550/2014-3).

This work is also funded by FEDER funds through the Competitivity Factors Operational Programme - COMPETE and by national funds through FCT - Foundation for Science and Technology within the scope of the project POCI-01-0145-FEDER-007136

This research was partially supported by the Strategic Funding UID/Multi/04423/2013 through national funds provided by FCT - Foundation for Science and Technology and European Regional Development Fund (ERDF), in the framework of the program PT2020. 


\section{References}

[1] M.L. Gulrajania, D. Gupta, Emerging techniques for functional finishing of textiles, Indian J. Fibre Text. Res. 36 (2011) 388-397.

[2] L. Sánchez-Silva, P. Sánchez, J.F. Rodríguez, Effective Method of Microcapsules Production for Smart Fabrics, in: M.A.D.S. Bernardes (Ed.), Dev. Heat Transf., InTech, Shanghai, 2011: pp. 649-666. doi:10.5772/18384.

[3] L. Van Langenhove, Textile-based drug release systems, in: L. Van Langenhove (Ed.), Smart Text. Med. Healthc. Mater. Syst. Appl., 1st Editio, Woodhead Publishing, Cambridge, 2007: p. 336. doi:10.1533/9781845692933.1.50.

[4] A.P.A. Filgueiras, R. Fangueiro, F. Soutinho, A importância de fibras e fios no design de têxteis destinados à prática desportiva, Estud. Em Des. 15 (2008) 20. http://repositorium.sdum.uminho.pt/handle/1822/25925.

[5] T. Ristić, L.F. Zemljič, M. Novak, M.K. Kunčič, S. Sonjak, N.G. Cimerman, S. Strnad, Antimicrobial efficiency of functionalized cellulose fibres as potential medical textiles, in: A. Méndez-Vilas (Ed.), Sci. against Microb. Pathog. Commun. Curr. Res. Technol. Adv., 2011: pp. 36-51.

[6] I. Cardoso, J.N.R. Gomes, The application of microcapsules of PCM in flame resistant non-woven materials, Int. J. Cloth. Sci. Technol. 21 (2009) 102-108. doi:10.1108/09556220910933826.

[7] D. Celcar, Influence of Phase-Change Materials on thermo-physiological comfort in warm e nvironment, J. Text. 2013 (2013) 1-9. doi:10.1155/2013/757319.

[8] K. Iqbal, D. Sun, Development of thermal stable multifilament yarn containing microencapsulated phase change materials, Fibers Polym. 16 (2015) 1156-1162. doi:10.1007/s12221-015-1156-9.

[9] S. Mondal, Phase change materials for smart textiles - An overview, Appl. Therm. Eng. 28 (2008) 1536-1550. doi:10.1016/j.applthermaleng.2007.08.009.

[10] A. Sharma, V. V. Tyagi, C.R. Chen, D. Buddhi, Review on thermal energy storage with phase change materials and applications, Renew. Sustain. Energy Rev. 13 (2009) 318-345. doi:10.1016/j.rser.2007.10.005.

[11] S. Mondal, Thermo-regulating textiles with phase-change materials, in: N. Pan, G. Sun (Eds.), Funct. Text. Improv. Performance, Prot. Heal., Woodhead Publishing Limited, Cambridge, 2011: p. 528. doi:10.1017/CBO9781107415324.004.

[12] F.A. Abdel-Mohdy, M.M.G. Fouda, M.F. Rehan, A.S. Aly, Repellency of controlledrelease treated cotton fabrics based on cypermethrin and prallethrin, Carbohydr. Polym. 73 (2008) 92-97. doi:10.1016/j.carbpol.2007.11.006.

[13] A. Vyas, S. Saraf, S. Saraf, Cyclodextrin based novel drug delivery systems, J. Incl. Phenom. Macrocycl. Chem. 62 (2008) 23-42. doi:10.1007/s10847-008-9456-y.

[14] H.-J. Buschmann, U. Denter, D. Knittel, E. Schollmeyer, The use of Cyclodextrins in textile processes - An overview, J. Text. Inst. 89 (1998) 554-561. doi:10.1080/00405009808658641.

[15] E.M.M. Del Valle, Cyclodextrins and their uses: A review, Process Biochem. 39 (2004) 1033-1046. doi:10.1016/S0032-9592(03)00258-9.

[16] J. Szejtli, Past, present, and future of Cyclodextrin r esearch, Pure Appl. Chem. 76 (2004) 1825-1845. doi:10.1002/chin.200517261.

[17] H.M.C. Marques, A review on cyclodextrin encapsulation of essential oils and volatiles, Flavour Fragr. J. 25 (2010) 313-326. doi:10.1002/ffj.2019.

[18] L. Cabrales, N. Abidi, A. Hammond, A. Hamood, Cotton fabric functionalization with cyclodextrins, J. Mater. Environ. Sci. 3 (2012) 561-574.

[19] H.J. Buschmann, D. Knittel, E. Schollmeyer, New textile applications of cyclodextrins, J. Incl. Phenom. 40 (2001) 169-172. doi:10.1023/A:1011892600388.

[20] U.R. Bhaskara-Amrit, P.B. Agrawal, M.M.C.G. Warmoeskerken, Applications of $\beta$ - 
Cyclodextrins in textiles, Autex Res. J. 11 (2011) 94-101.

[21] H. Reuscher, R. Hirsenkorn, BETA W7 MCT - new ways in surface modification, Munchen, 1996. http://www.springerlink.com/index/U6282UG4022M5102.pdf.

[22] A. Bereck, Cyclodextrins in textile finishing: Fixation and analysis, Adv. Mater. Res. 93-94 (2010) 1-4. doi:10.4028/www.scientific.net/AMR.93-94.1.

[23] M. Ghannoum, N. Isham, Fungal nail infections (Onychomycosis): A never-ending story?, PLoS Pathog. 10 (2014) 1-5. doi:10.1371/journal.ppat.1004105.

[24] H. Sanada, G. Nakagami, K. Takehara, T. Goto, N. Ishii, S. Yoshida, M. Ryu, Y. Tsunemi, Antifungal Effect of Non-Woven Textiles Containing Polyhexamethylene Biguanide with Sophorolipid: A Potential Method for Tinea Pedis Prevention, Healthcare. 2 (2014) 183-191. doi:10.3390/healthcare2020183.

[25] M.M. Cowan, Plant products as antimicrobial agents., Clin. Microbiol. Rev. 12 (1999) 564-82. doi:0893-8512/99/\$04.00 $\square 0$.

[26] M. Joshi, S.W. Ali, S. Rajendran, Antibacterial finishing of polyester/cotton blend fabrics using neem (azadirachta indica): A natural bioactive agent, J. Appl. Polym. Sci. 106 (2007) 793-800. doi:DOI 10.1002/app.26323.

[27] E. Pinto, L. Vale-Silva, C. Cavaleiro, L. Salgueiro, Antifungal activity of the clove essential oil from Syzygium aromaticum on Candida, Aspergillus and dermatophyte species, J. Med. Microbiol. 58 (2009) 1454-1462. doi:10.1099/jmm.0.010538-0.

[28] B. Simoncic, B. Tomsic, Structures of novel antimicrobial agents for textiles - A review, Text. Res. J. 80 (2010) 1721-1737. doi:10.1177/0040517510363193.

[29] E. Pinto, K. Hrimpeng, G. Lopes, S. Vaz, M.J. Gon??alves, C. Cavaleiro, L. Salgueiro, Antifungal activity of Ferulago capillaris essential oil against Candida, Cryptococcus, Aspergillus and dermatophyte species, Eur. J. Clin. Microbiol. Infect. Dis. 32 (2013) 1311-1320. doi:10.1007/s10096-013-1881-1.

[30] D. Kalemba, A. Kunicka, Antibacterial and antifungal properties of essential oils., Curr. Med. Chem. 10 (2003) 813-829.

http://www.ncbi.nlm.nih.gov/pubmed/12678685.

[31] C. Pina-Vaz, A.G. Rodrigues, E. Pinto, Costa-de-Oliveira, C. Tavares, L. Salgueiro, C. Cavaleiro, M.J. Gonçalves, J. Martinez-de-Oliveira, Antifungal activity of Thymus oils and their major compounds, J. Eur. Acad. Dermatology Venereol. 18 (2004) 73-78. doi:10.2298/ABS1404539S.

[32] A. Nostro, A.S. Roccaro, G. Bisignano, A. Marino, M.A. Cannatelli, F.C. Pizzimenti, P.L. Cioni, F. Procopio, A.R. Blanco, Effects of oregano, carvacrol and thymol on Staphylococcus aureus and Staphylococcus epidermidis biofilms, J. Med. Microbiol. 56 (2007) 519-523. doi:10.1099/jmm.0.46804-0.

[33] K.S.D.L. Mota, F.D.O. Pereira, W.A. De Oliveira, I.O. Lima, E. De Oliveira Lima, Antifungal activity of thymus vulgaris 1 . essential oil and its constituent phytochemicals against rhizopus oryzae: Interaction with ergosterol, Molecules. 17 (2012) 14418-14433. doi:10.3390/molecules 171214418.

[34] S. Abbaszadeh, A. Sharifzadeh, H. Shokri, A.R. Khosravi, A. Abbaszadeh, Antifungal efficacy of thymol, carvacrol, eugenol and menthol as alternative agents to control the growth of food-relevant fungi, J. Mycol. Med. 24 (2014) 51-56. doi:10.1016/j.mycmed.2014.01.063.

[35] A. Goel, S.N. Nene, Modifications in the Phenolphthalein Method for Spectrophotometric Estimation of Beta Cyclodextrin, Starch / Starke. 47 (1995) 399 400. doi:10.1002/star.19950471006.

[36] V.A. Dehabadi, H.-J. Buschmann, J.S. Gutmann, Spectrophotometric estimation of the accessible inclusion sites of b-cyclodextrin fixed on cotton fabrics using phenolic dyestuffs, Anal. Methods. 6 (2014) 3382-3387. doi:10.1039/C4AY00293H.

[37] S.S. Latthe, A.B. Gurav, C.S. Maruti, R.S. Vhatkar, Recent progress in preparation of superhydrophobic surfaces: a review, J. Surf. Eng. Mater. Adv. Technol. 2 (2012) 76- 
94.

[38] V. Sacevičienè, M. Jucienè, V. Bieliūnienè, V. Čepauskienė, V. Urbelis, Investigation of the wettability of the hydrophobic textile after mechanical treatments, Proc. Est.

Acad. Sci. 64 (2015) 118-123. doi:10.3176/proc.2015.1S.08.

[39] R.W. Korsmeyer, R. Gurny, E. Doelker, P. Buri, N.A. Peppas, Mechanisms of solute release from porous hydrophilic polymers, Int. J. Pharm. 15 (1983) 25-35. doi:10.1016/0378-5173(83)90064-9.

[40] S. Khanna, S. Sharma, J.N. Chakraborty, Performance assessment of fragrance finished cotton with cyclodextrin assisted anchoring hosts, Fash. Text. 2 (2015) 1-17. doi:10.1186/s40691-015-0042-9.

[41] K.J. Waleczek, H.M.C. Marques, B. Hempel, P.C. Schmidt, Phase solubility studies of pure (-)- $\alpha$-bisabolol and camomile essential oil with $\beta$-cyclodextrin, Eur. J. Pharm. Biopharm. 55 (2003) 247-251. doi:10.1016/S0939-6411(02)00166-2.

[42] L. Szente, J. Szejtli, Cyclodextrins as food ingredients, Trends Food Sci. Technol. 15 (2004) 137-142. doi:10.1016/j.tifs.2003.09.019.

[43] G. Sacchetti, S. Maietti, M. Muzzoli, M. Scaglianti, S. Manfredini, M. Radice, R. Bruni, Comparative evaluation of 11 essential oils of different origin as functional antioxidants, antiradicals and antimicrobials in foods, Food Chem. 91 (2005) 621-632. doi:10.1016/j.foodchem.2004.06.031.

[44] E.E. Lazar-Baker, S.D. Hetherington, V. V. Ku, S.M. Newman, Evaluation of commercial essential oil samples on the growth of postharvest pathogen Monilinia fructicola (G. Winter) Honey, Lett. Appl. Microbiol. 52 (2011) 227-232. doi:10.1111/j.1472-765X.2010.02996.X.

[45] M. Jouki, S.A. Mortazavi, F.T. Yazdi, A. Koocheki, Characterization of antioxidantantibacterial quince seed mucilage films containing thyme essential oil, Carbohydr. Polym. 99 (2014) 537-546. doi:10.1016/j.carbpol.2013.08.077.

[46] E. Locci, S. Lai, A. Piras, B. Marongiu, A. Lai, C-CPMAS and H-NMR study of the inclusion complexes of $\beta$-cyclodextrin with carvacrol, thymol, and eugenol prepared in supercritical carbon dioxide, Chem. Biodivers. 1 (2004) 1354-1366. doi:10.1002/cbdv.200490098.

[47] A. Rukmani, M. Sundrarajan, Inclusion of antibacterial agent thymol on $\beta$ cyclodextrin-grafted organic cotton, J. Ind. Text. 42 (2011) 132-144. doi:10.1177/1528083711430244.

[48] M. Sundrarajan, A. Rukmani, Durable antibacterial finishing on organic cotton by inclusion of thymol into cyclodextrin derivative, E-Journal Chem. 9 (2012) 1511-1517. doi:10.1155/2012/863674.

[49] E. Pinho, M. Grootveld, G. Soares, M. Henriques, Cyclodextrins as encapsulation agents for plant bioactive compounds., Carbohydr. Polym. 101 (2014) 121-35. doi:10.1016/j.carbpol.2013.08.078.

[50] K. Bethanis, P. Tzamalis, F. Tsorteki, A. Kokkinou, E. Christoforides, D. Mentzafos, Structural study of the inclusion compounds of thymol, carvacrol and eugenol in $\beta$ cyclodextrin by X-ray crystallography, J. Incl. Phenom. Macrocycl. Chem. 77 (2013) 163-173. doi:10.1007/s10847-012-0230-9.

[51] A.G. Guimarães, M.A. Oliveira, R.D.S. Alves, P.D.P. Menezes, M.R. Serafini, A.A. De Souza Araújo, D.P. Bezerra, L.J. Quintans, Encapsulation of carvacrol, a monoterpene present in the essential oil of oregano, with $\beta$-cyclodextrin, improves the pharmacological response on cancer pain experimental protocols, Chem. Biol. Interact. 227 (2015) 69-76. doi:10.1016/j.cbi.2014.12.020.

[52] E.H. Santos, J.A. Kamimura, L.E. Hill, C.L. Gomes, Characterization of carvacrol beta-cyclodextrin inclusion complexes as delivery systems for antibacterial and antioxidant applications, LWT - Food Sci. Technol. 60 (2015) 583-592. doi:10.1016/j.lwt.2014.08.046. 
[53] I. Mourtzinos, N. Kalogeropoulos, S.E. Papadakis, K. Konstantinou, V.T. Karathanos, Encapsulation of nutraceutical monoterpenes in beta-cyclodextrin and modified starch, J. Food Sci. 73 (2008) 89-94. doi:10.1111/j.1750-3841.2007.00609.x.

[54] F. Tao, L.E. Hill, Y. Peng, C.L. Gomes, Synthesis and characterization of $\beta$ cyclodextrin inclusion complexes of thymol and thyme oil for antimicrobial delivery applications, LWT - Food Sci. Technol. 59 (2014) 247-255. doi:10.1016/j.lwt.2014.05.037.

[55] W. Sricharussin, C. Sopajaree, T. Maneerung, N. Sangsuriya, Modification of cotton fabrics with $\beta$-cyclodextrin derivative for aroma finishing, J. Text. Inst. 100 (2009) 682-687. doi:10.1080/00405000802158999.

[56] H. Issazadeh- Baltorki, A. Khoddami, Cyclodextrin-coated denim fabrics as novel carriers for ingredient deliveries to the skin, Carbohydr. Polym. 110 (2014) 513-517. doi:10.1016/j.carbpol.2014.03.008.

[57] J.S. Hwang, J.N. Kim, Y.J. Wee, J.S. Yun, H.G. Jang, S.H. Kim, H.W. Ryu, Preparation and characterization of melamine-formaldehyde resin microcapsules containing fragrant oil, Biotechnol. Bioprocess Eng. 11 (2006) 332-336. doi:10.1007/BF03026249.

[58] V. Popescu, I. Sandu, E.I. Muresan, B. Istrate, G. Lisa, Effects of the pre-treatment with atmospheric - Air plasma followed by conventional finishing, Rev. Chim. 65 (2014) 676-683.

[59] J.I.N. Gomes, C.J.E. Lima, Double walled microcapsules with an outer thermoplastic wall and application., 2005.

[60] Y. Wang, The uniform Si-O coating on cotton fibers by an atmospheric pressure plasma treatment, J. Macromol. Sci. 50 (2011) 1739-1746. doi:10.1080/00222348.2010.549051.

[61] A. Grigoriu, C. Luca, G. Lisa, A. Grigoriu, On the Thermal Stability of Flax Fabrics Grafted with Monochlorotriazinyl- $\beta$-Cyclodextrin and Treated with Cinnamic Derivates, Cellul. Chem. Technol. 43 (2009) 153-161.

[62] P. Sánchez, M.V. Sánchez-Fernandez, A. Romero, J.F. Rodríguez, L. Sánchez-Silva, Development of thermo-regulating textiles using paraffin wax microcapsules, Thermochim. Acta. 498 (2010) 16-21. doi:10.1016/j.tca.2009.09.005.

[63] M. Karthikeyan, K. Visagavel, T. Ramachandran, M. Ilangkumuran, M. Kirubakaran, Innovation in textiles : integration of nanoencapsulation of PCMs in cotton fabric, in: Int. Conf. Syst. Sci. Control. Commun. Eng. Technol., 2015: pp. 85-91.

[64] S. Demirbağ, S.A. Aksoy, Encapsulation of phase change materials by complex coacervation to improve thermal performances and flame retardant properties of the cotton fabrics, Fibers Polym. 17 (2016) 408-417. doi:10.1007/s 12221-016-5113-z.

[65] K. Koo, J. Choe, Y. Park, The application of PCMMcs and SiC by commercially direct dual-complex coating on textile polymer, Appl. Surf. Sci. 255 (2009) 8313-8318. doi:10.1016/j.apsusc.2009.05.039.

[66] F.R. Oliveira, M. Fernandes, N. Carneiro, A. Pedro Souto, Functionalization of wool fabric with phase-change materials microcapsules after plasma surface modification, J. Appl. Polym. Sci. 128 (2013) 2638-2647. doi:10.1002/app.38325.

[67] F. Ferrero, M. Periolatto, Modification of surface energy and wetting of textile fibers, in: M. Aliofkhazraei (Ed.), Modif. Surf. Energy Wetting Text. Fibers, Wetting Wettability, InTech, InTech, 2015. doi:10.5772/60812.

[68] S. Shahidi, N. Aslan, M. Ghoranneviss, M. Korachi, Effect of thymol on the antibacterial efficiency of plasma-treated cotton fabric, Cellulose. 21 (2014) 19331943. doi:10.1007/s10570-014-0250-2.

[69] S. Milovanovic, M. Stamenic, D. Markovic, M. Radetic, I. Zizovic, Solubility of thymol in supercritical carbon dioxide and its impregnation on cotton gauze, J. Supercrit. Fluids. 84 (2013) 173-181. doi:10.1016/j.supflu.2013.10.003. 
[70] J. Wang, B.M. Wang, S.P. Schwendeman, Mechanistic evaluation of the glucoseinduced reduction in initial burst release of octreotide acetate from poly(D,L-lactideco-glycolide) microspheres, Biomaterials. 25 (2004) 1919-1927.

doi:10.1016/j.biomaterials.2003.08.019.

[71] P.L. Ritger, N.A. Peppas, A simple equation for description of solute release I. Fickian and Non-Fickian release from Non-Sweliable devices in the form of slabs, spheres, cylinders or discs, J. Control. Release. 5 (1987) 23-36.

[72] N.A. Peppas, B. Narasimhan, Mathematical models in drug delivery: How modeling has shaped the way we design new drug delivery systems, J. Control. Release. 190 (2014) 75-81. doi:10.1016/j.jconrel.2014.06.041.

[73] P.L. Sóti, Z.K. Nagy, G. Serneels, B. Vajna, A. Farkas, F. Van Der Gucht, P. Fekete, T. Vigh, I. Wagner, A. Balogh, H. Pataki, G. Mezo, G. Marosi, Preparation and comparison of spray dried and electrospun bioresorbable drug delivery systems, Eur. Polym. J. 68 (2015) 671-679. doi:10.1016/j.eurpolymj.2015.03.035.

[74] P.I. Lee, Kinetics of drug release from hydrogel matrices, J. Control. Release. 2 (1985) 277-288. doi:10.1016/0168-3659(85)90051-3. 